\title{
Mass Transfer in a Gas-Solid Packed Column at Trickle Flow
}

\author{
A W M ROES and W P. M VAN SWAAIJ \\ Twente University of Technology, Department of Chemical Engineering, PO Box 217, Enschede (The \\ Netherlands)
}

(Received 1 June 1978, in final form 25 October 1978)

\section{Abstract}

The height of an overall transfer unit has been evaluated in a gas-solid packed column at trickle flow by measuring column performance during steady state adsorption experiments. Results have been interpreted with an extraction model mass transfer and axial dispersion in both phases Using Bodenstein numbers for the gas and solid phases from a previous investigation the height of a true transfer unit has been calculated

The column was filled with dumped Pall rings, the solid phase was a freely flowing catalyst carrer, and the gas phase was air at amblent conditions containing freon-12 as adsorbing component.

At low gas velocities column performance is entirely determined by axual dispersion but at higher gas velocities mass transfer limitations become important. For conditions of practical importance the height of a true transfer unit corresponds to 4-9 Pall ring layers.

\section{INTRODUCTION}

A gas-solid packed column at trickle flow seems to be a promising new contactor in gas-solid countercurrent processes [ 1 - 3] . In this operation fune particles flow in trickles over an open packing (e.g Pall nings, cylindrical screens) in countercurrent to a gas. The main advantages of this type of operation are the low pressure drop and low axial dispersion of both phases, operational flexıbility and simple construction.

In a previous paper [2] we showed a close similarity between gas-solid and gas-liquid systems (see also ref 1 ). Phenomena like loading and flooding occurred; solid hold-up could be split into a static and dynamic part. Pressure drop was low because only part of the solid was suspended in the air stream.

In adsorption processes column performance is strongly influenced by axial dispersion in both phases and by interphase mass transfer. Axial dispersion has been examined in a previous investigation [3]. From pulse response experiments the authors determined the Bodenstein numbers for the gas and solid phases. For conditions of practical importance the height of a mixing unit ( $=2 d_{\mathrm{p}} / \mathrm{Bo}$ ) corresponded to $5-15$ packing layers for the solid phase and to 2 - 5 for the gas phase.

The present investigation deals with the determination of the mass transfer between gas and solid phases. The height of an overall transfer unit (also often called height of a piston flow [4] or apparent [5] transfer unit) can be evaluated from the logarithmic mean driving force at the entrance and outlet. Since axial dispersion and the extraction factor have been determined in an independent way it is possible to calculate the height of a true transfer unit.

\section{THEORY}

In the earliest papers concerning continuous countercurrent processes, axial dispersion of the phases was not taken into account. Column performance was described by the concepts of theoretical plates or overall transfer units. The number of overall transfer units for our system can be evaluated from the following equation:

$$
N_{k \text { ov }}=\frac{1}{1-F} \ln \frac{C_{\mathrm{gin}}-C_{\mathrm{sout}} / m}{C_{\mathrm{g} \text { out }}-C_{\mathrm{sin}} / m} \quad F \neq 1
$$


$N_{k \text { ov }}=\frac{C_{\mathrm{g} \text { in }}-C_{\mathrm{gout}}}{C_{\mathrm{gin}}-C_{\text {sout }} / m} \quad F=1$

$C_{\mathrm{g}}$ and $C_{\mathrm{s}}$ are concentrations in the gas phase (expressed in $\mathrm{kg} / \mathrm{m}^{3}$ gas) and on the solid phase (expressed in $\mathrm{kg} / \mathrm{m}^{2}$ internal surface area of solid material), respectively, $m$ is the adsorption equilibrium constant and $F$ the extraction factor defined according to

$F=\frac{u_{\mathrm{g}}}{m a_{\mathrm{mt}} u_{\mathrm{s}}}$

For a more realistic outline, axial muxing within both phases should be taken into account. In the present investigation we assume that the adsorption process may be described by the model interphase mass transfer and axially dispersed plug flow [4]. The governing differentıal equations for the steady state are given by (see Fig. 1):

gas phase

$\frac{\mathrm{d} C_{\mathrm{g}}}{\mathrm{d} \xi}-\frac{1}{\mathrm{Pe}} \frac{\mathrm{d}_{\mathrm{g}}^{2} C_{\mathrm{g}}}{\mathrm{d} \xi^{2}}+N_{k}\left(C_{\mathrm{g}}-\frac{C_{\mathrm{s}}}{m}\right)=0$

solld phase

$\frac{\mathrm{d}\left(C_{\mathrm{s}} / m\right)}{\mathrm{d} \xi}+\frac{1}{\mathrm{Pe}_{\mathrm{s}}} \frac{\mathrm{d}^{2}\left(C_{\mathrm{s}} / m\right)}{\mathrm{d} \xi^{2}}+N_{k} F\left(C_{\mathrm{g}}-\frac{C_{\mathrm{s}}}{m}\right)=0$

where $\mathrm{Pe}_{\mathrm{g}}$ and $\mathrm{Pe}_{\mathrm{s}}$ are the Peclet numbers of the gas and solid phase, respectively, $N_{k}$ is the number of true transfer units and $\xi$ the

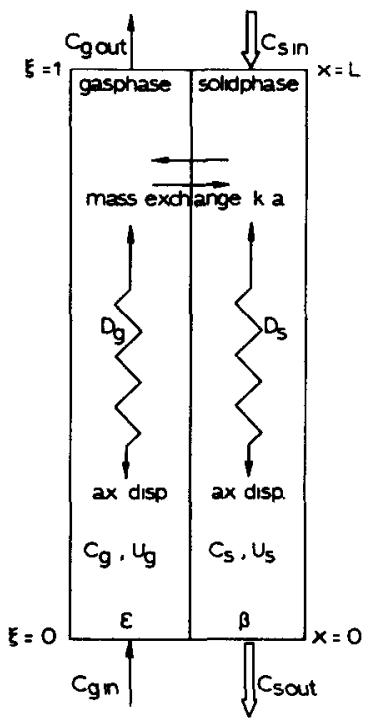

Fig 1 Extraction model according to Miyauchı and Vermeulen [4] dimensionless length coordinate. The dimensionless groups are given by

$\mathrm{Pe}_{\mathrm{g}}=\mathrm{Bo}_{\mathrm{g}} \frac{L}{d_{\mathrm{p}}}=\frac{u_{\mathrm{g}} L}{\epsilon D_{\mathrm{g}}}$

$\mathrm{Pe}_{\mathrm{s}}=\mathrm{Bo}_{\mathrm{s}} \frac{L}{d_{\mathrm{p}}}=\frac{u_{\mathrm{s}} L}{\beta D_{\mathrm{s}}}$

$N_{k}=\frac{k a L}{u_{\mathrm{g}}}$ and $\xi=\frac{x}{L}$

The boundary conditions for differential equations (1) and (2) are assumed to be represented by the well-known Danckwerts equations [6]:

gas inlet, $\xi=0$

$$
\begin{aligned}
-\frac{1}{\mathrm{Pe}_{\mathrm{g}}} \frac{\mathrm{d} C_{\mathrm{g}}\left(0^{+}\right)}{\mathrm{d} \xi}+C_{\mathrm{g}}\left(0^{+}\right) & =C_{\mathrm{g}}\left(0^{-}\right) \\
& =C_{\mathrm{g} \text { in }}
\end{aligned}
$$$$
\xi=0
$$

$\frac{1}{\mathrm{Pe}_{\mathrm{s}}} \frac{\mathrm{d}\left(C_{\mathrm{s}}(0) / m\right)}{\mathrm{d} \xi}-0$

gas outlet, $\xi=1$

$$
\begin{aligned}
& \frac{1}{\mathrm{Pe}_{\mathrm{g}}} \frac{\mathrm{d} C_{\mathrm{g}}(1)}{\mathrm{d} \xi}=0 \\
& \frac{1}{\mathrm{Pe}_{\mathrm{s}}} \frac{\mathrm{d}\left(C_{\mathrm{s}}\left(1^{-}\right) / m\right)}{\mathrm{d} \xi}+\frac{C_{\mathrm{s}}}{m}\left(1^{-}\right)=\frac{C_{\mathrm{s}}}{m}\left(1^{+}\right) \\
& =\frac{C_{\mathrm{sin}}}{m}
\end{aligned}
$$

Many theoretical investigations have been carried out on the numencal or analytical solution of the set of equations (4) - (6) (e g. refs. 4, 7 and 8). Analytical solutions have been given by Miyauchi and Vermeulen [4] and by Hartland and Mecklenburgh [8] . From their expressions concentration profiles inside the column can be calculated. On the other hand, if the concentration profiles are known it is possible to calculate the model parameters by curve fitting ( $e g$ refs. 9 and 10).

An alternative way to determine the number of true transfer units (which was used in the present investigation) is the use of relatively simple approximations of the complete analytical solution. Misek and Rod have given a literature survey of the approximations derived by different authors [11]. In 
Appendix A the solutions obtained by Beek [12], Stemerding and Zuiderweg [5], Miyauchı and Vermeulen [4], Mecklenburgh and Hartland [13] and Rod [14] are summarized. The relations are presented in the general form

$N_{k \text { ov }}=f\left(N_{k}, \mathrm{Pe}_{\mathrm{g}}, \mathrm{Pe}_{\mathrm{s}}, F\right)$

The number of overall transfer units can be calculated from eqn. (1a/1b). Combination with eqn. (7) after insertion of $\mathrm{Pe}_{\mathrm{g}}, \mathrm{Pe}_{\mathrm{s}}$ and $F$ allows the determination of $N_{k}$, the number of true transfer units

\section{EXPERIMENTAL SYSTEM}

The experimental arrangement (see Fig. 2) consisted of two packed columns, an adsorber and a stmpper, interconnected by pneumatic transport lines. In the adsorber column four parts may be distinguished: on top, a disengaging section; the packed section (length $1.00 \mathrm{~m}$, internal diameter $0.075 \mathrm{~m}$ ); a measuring section containing two air inlets and three valves; and finally a fluid bed.

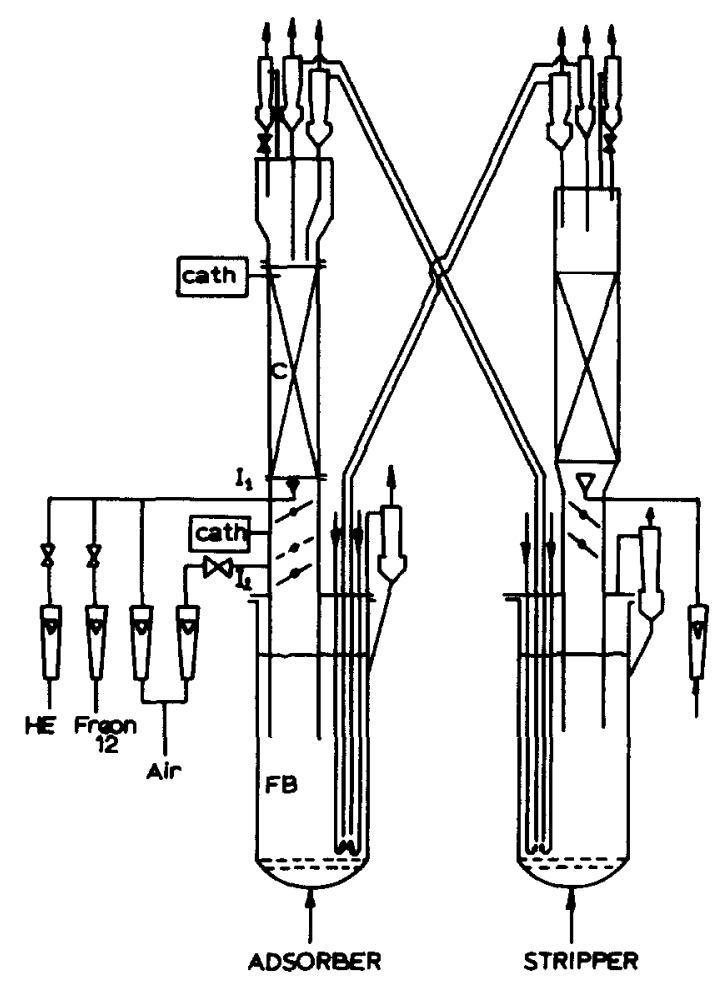

Fig. 2. Schematic diagram of experimental system: $C$, column, CATH, catharometer; FB, flud bed; $I_{1,2}$, air inlets
Aur at ambient conditions enters the adsorber by $I_{2}$, passes through the packing and the disengaging section and leaves the column via a cyclone where the entrained particles are collected. The particles are transported pneumatically from the fluid bed of the desorption column to the adsorber. They are separated from the carrier gas in two cyclones and enter the column via two diplegs on top of the packing. A cone was inserted in the end of the diplegs to ensure a good initial distribution of the solid over the packıng. After flowing through the packing the particles pass through the measuring sectron and enter the fluid bed which is maintained just above minımum bubbling conditions to reduce the internal friction of the particles. From this flund bed a dense gassolid mixture is transported to the stripper where the particles follow a simular course as in the adsorber. In the strip column (with an internal diameter of $0.10 \mathrm{~m}$ and length $0.6 \mathrm{~m}$ ) the adsorbed freon is stripped off.

Both columns were filled with dumped Pall rings, the properties of which are given in Table 1.

\section{TABLE 1}

Properties of Pall rings

\begin{tabular}{ll}
\hline$d_{p}$ & $0015 \mathrm{~m}$ \\
$\delta$ & $0002 \mathrm{~m}$ \\
$a_{\mathrm{p}}$ & $310 \mathrm{~m}^{2} / \mathrm{m}^{3}$ \\
$\epsilon_{\mathrm{p}}$ & 086 \\
$N$ & $22 \times 10^{5} \mathrm{~m}^{-3}$ \\
\hline
\end{tabular}

The gas phase was air at ambient condltions. The solid was a porous catalyst carner, the properties of which are given in Table 2.

Freon-12 was used as adsorbing gas. The adsorption isotherm was found to be a straight line below 3 vol.\% freon in air; the equilibrium constant for our system has been measured within our group [15] with a chromatographic column:

$$
\begin{aligned}
m & =\left(\frac{C_{\mathrm{s}}}{C_{\mathrm{g}}}\right)_{\text {equilibrium }} \\
& =48.3 \times 10^{-9} \frac{\mathrm{kg} / \mathrm{m}^{2} \text { surface area }}{\mathrm{kg} / \mathrm{m}^{3} \text { gas phase }}
\end{aligned}
$$

During the experiments the freon concentration was always kept below 2 vol.\%. 
TABLE 2

Properties of the particles

\begin{tabular}{ll}
\hline Composition & 87 wt $\% \mathrm{SiO}_{2}$ \\
& 129 wt $\% \mathrm{Al}_{2} \mathrm{O}_{3}$
\end{tabular}

Particle diameter distribution

\begin{tabular}{lrl} 
Diameter & Wt $\%$ & \multicolumn{1}{l}{ Cumulative wt \% } \\
$<45$ & 73 & 73 \\
$45-75$ & 305 & 378 \\
$75-105$ & 239 & 617 \\
$105-150$ & 369 & 980 \\
$150-210$ & 16 & 996 \\
$210-300$ & 03 & 999 \\
$>300$ & 01 & 100 \\
& & $\pm 70 \times 10^{-6} \mathrm{~m}$ \\
Mean particle diameter & $2200 \mathrm{~kg} / \mathrm{m}^{3}$ \\
Skeletal density & & $813 \mathrm{~kg} / \mathrm{m}^{3}$ \\
Particle density & 063 \\
Particle void fraction & $540 \times 10^{3} \mathrm{~m}^{2} / \mathrm{kg}$ \\
Internal surface area &
\end{tabular}

Gas velocity was measured with a rotameter, the measurement of the solid mass flux has been described elsewhere [2]. The freon concentration in the gas phase was determined with a catharometer which was found to be linear up to $10 \mathrm{vol} . \%$ freon in air.

The freon outlet concentration in the gas phase was determined $0.03 \mathrm{~m}$ below the packing level. Measurements on the packing level were disturbed by air which left the diplegs together with the particles. We ascertaned in the followng way that this effect did not occur $0.03 \mathrm{~m}$ below the packing level. At the gas inlet $I_{1}$ helium (which does not adsorb on the solid [3]) was added to the gas phase. If the helium concentration was measured on the packing level near the diplegs the helium concentration decreased if solnd flow commenced. This diluting effect caused by air coming out of the diplegs was absent $0.03 \mathrm{~m}$ below the packing level. The freon inlet concentration in the gas phase was measured after interrupting the solid flow.

The stripper column was operated at a superficial gas velocity of at least $01 \mathrm{~m} / \mathrm{s}$ to ensure that the inlet concentration on the solid phase in the adsorber was zero. We checked this in the following way. First the columns were operated (freon adsorption in the adsorber, desorption in the desorber) until the steady state was reached. Next the gas flow to the risers and fluid beds was cut off simultaneously by means of solenoid valves. Then the packing of the adsorber was stripped with air to remove the remaining freon. After air stripping was stopped solid flow was restarted to collect a layer of about $0.1 \mathrm{~m}$ solid material on valve $V_{2}$ in the adsorber column. This valve contained a porous plate distributor. The collected particles were stripped with aur entering by $I_{2}$ and the outlet concentration was monitored continuously. No freon was detected in the aur stream.

The freon concentration on the solid in the adsorber exit was determined in an indirect way Below aur inlet $I_{1}$, the gas velocity is approximately zero and the particles reach equilibrium with their surroundings. Thus by sampling below the gas inlet the measured concentration in the gas phase in the steady state is equal to $C_{\text {sout }} / \mathrm{m}$. This has been checked by collecting particles on valve $V_{2}$ and performing the same strip experment as outlined previously.

\section{RESULTS}

During the experiments the inlet and outlet concentrations in the gas phase and the outlet concentration on the solid phase were measured as described above. Initially the packung height in the adsorber was $1.00 \mathrm{~m}$. This height was found to be too large since the solid phase near the outlet was nearly always in equilibnum with the incoming gas phase and, if not, the ratio of the outlet and inlet concentrations in the gas phase was often smaller than 0.1 . For this reason we decided to reduce the packing height to $0.5 \mathrm{~m}$.

Figures 3 and 4 show the dimensionless outlet concentrations in the gas and solid phases, respectively. From these Figures it can be seen that the dimensionless outlet concentrations in the gas and solid phases increase with increasing gas velocity and decreasing solid mass flux, as can be expected. At low gas velocities the outlet concentration in the gas phase becomes very low, therefore it is possible to calculate the asymptote of the outlet concentration on the solid phase for these conditions assuming that all the freon leaves the column adsorbed on the solid phase: 


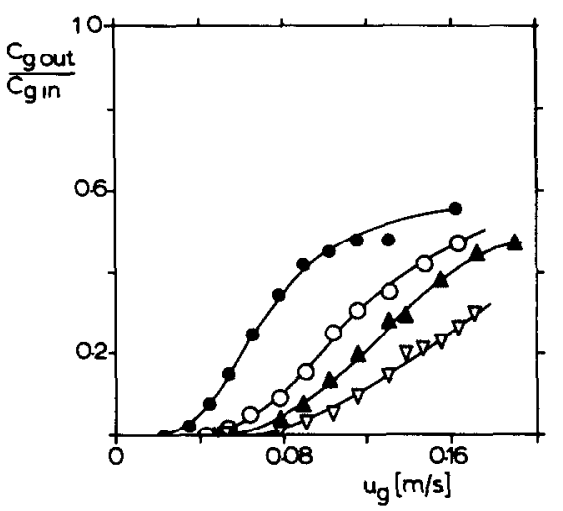

Fig 3 Dimensionless outlet concentration in gas phase versus superficial gas velocity

$\begin{array}{ll}\text { Symbol } & S\left(\mathbf{k g} / \mathrm{m}^{2} \mathrm{~s}\right) \\ \bullet & 233 \\ \circ & 389 \\ \Delta & 466 \\ \nabla & 589\end{array}$

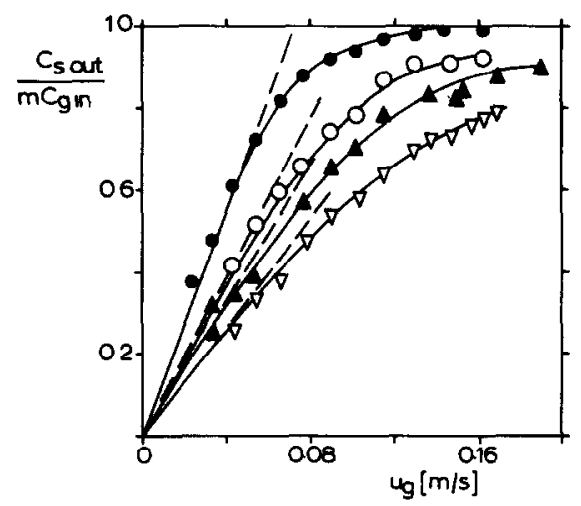

Fig 4 Dimensionless outlet concentration on solid phase versus superficial gas velocity Symbols see Fig 3

$\frac{C_{\text {s out }}}{m C_{\text {g In }}}=F$

The broken lines in Fig. 4 were calculated according to eqn. (8). From this Figure it can be concluded that the freon mass balance is correct for these conditions since the experimental data approximate the theoretical asymptotes very well. The freon mass balance was checked for each experiment and it never deviated more than $10 \%$ from its theoretical value. These deviations should be accepted as being due to possible expenmental errors in solid mass flux, gas velocity, etc

From eqn. (1a/1b) and the experimental data of Figs. 3 and 4 it is possible to calculate the number of overall transfer units as plotted in Fig 5. At low gas velocities the outlet

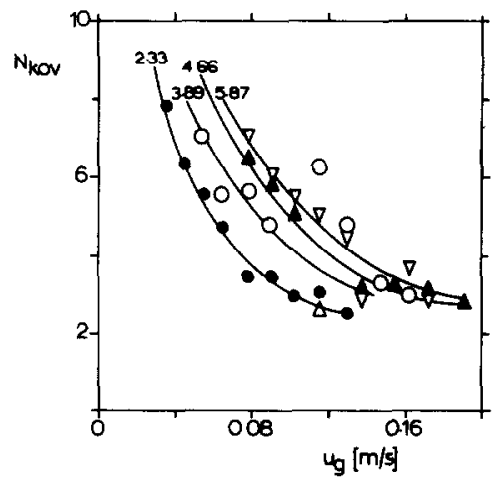

Fig 5 Number of overall mass transfer units versus superficial gas velocity Symbols see Fig 3

concentration on the solid phase is almost in equilibrium with the inlet concentration in the gas phase and consequently the number of transfer units is large. The number of overall transfer units decreases if gas velocity increases and increases slightly if solid mass flux increases at a given gas velocity.

As already mentioned in the theoretical part, it is possible to calculate the number of true transfer units if axial dispersion in both phases is known. This has been determined experimentally by means of residence time distribution experiments in a previous investigation. In Fig. 6 the Bodenstein number (Peclet number based on nominal packing diameter) for the gas and solid phases is plotted agaunst superficial gas velocity [3] The Peclet numbers for a given packing height follow from $\mathrm{Pe}=\mathrm{Bo} L / d_{\mathrm{p}}$. The extraction

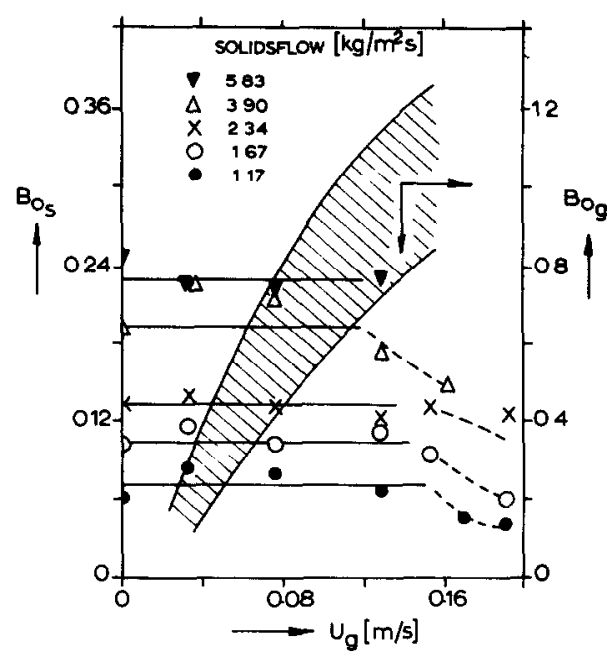

Fig 6 Bodenstein numbers for gas and solid phases versus superficial gas velocity. 
TABLE 3

Comparison of heights of a true transfer unit obtanned by various approxımating solutions

\begin{tabular}{|c|c|c|c|c|c|c|c|c|c|}
\hline \multirow{2}{*}{$\begin{array}{l}u_{g} \\
(\mathrm{~m} / \mathrm{s})\end{array}$} & \multirow{2}{*}{$\begin{array}{l}S \\
\left(\mathrm{~kg} / \mathrm{m}^{2} \mathrm{~s}\right)\end{array}$} & \multirow[t]{2}{*}{$F$} & \multirow[t]{2}{*}{$N_{k}$ ov } & \multirow[t]{2}{*}{$\mathbf{P e}_{\mathrm{g}}$} & \multirow[t]{2}{*}{$\mathbf{P e}_{8}$} & \multicolumn{4}{|l|}{$H_{k}(\mathrm{~m})$} \\
\hline & & & & & & $\begin{array}{l}\text { Stemerding } \\
\text { Zuiderweg }\end{array}$ & $\begin{array}{l}\text { Miyauchı } \\
\text { Vermeulen }\end{array}$ & $\begin{array}{l}\text { Mecklenb } \\
\text { Hartland }\end{array}$ & Rod \\
\hline 0090 & 389 & 089 & 484 & 22 & 63 & 0.020 & 0022 & 0020 & 0018 \\
\hline 0102 & 466 & 084 & 518 & 25 & 70 & 0022 & 0024 & 0022 & 0021 \\
\hline 0130 & 589 & 085 & 450 & 30 & 81 & 0047 & 0048 & 0048 & 0046 \\
\hline 0172 & 589 & 112 & 300 & 35 & 81 & 0094 & 0096 & 0105 & 0094 \\
\hline
\end{tabular}

factor can be determined from eqn. (2). The number of true transfer units then may be obtained from eqn. (7) (see also Appendix A) by trial and error. Table 3 presents some results for the height of a true transfer unit $\left(H_{k}=L / N_{k}\right)$ calculated with the different approximations.

At low gas velocities the height of a true mass transfer unit becomes low and therefore it is very difficult to calculate accurately ( $H_{k}$ sometimes becomes negative, which is physically impossible and must be ascribed to experimental error and/or approximation errors). The results obtained with the different methods agreed well; absolute differences in the height of a true mass transfer unit calculated in the various ways were never larger than $0.02 \mathrm{~m}$, which is within the order of magnitude of the experimental error.

In Fig. 7 the height of a true transfer unit calculated by Stemerding and Zuiderweg's approximation is plotted against superficial gas velocity. At low gas velocities the true height of a transfer unit is very small and it increases with increasing gas velocity The height of a true mass transfer unit increases rapidly with superficial gas velocity. The influence of solid mass flux on the true height of a transfer unit seems to be of minor importance.

The determining factor for column performance can easily be found from the following relation which holds near $F=1$ (see Appendix A) $[4,5,12,14,16]$ :

$$
\begin{array}{rlrl}
H_{k \text { ov }} & =H_{k}+\frac{L}{\mathrm{Pe}_{\mathrm{g}}}+\frac{L}{\mathrm{Pe}_{\mathrm{s}}} & & L \gg H_{\mathrm{DU}} \\
& =H_{k}+H_{\mathrm{DU}} & F & =1
\end{array}
$$

The height of an overall transfer unit at $F=1$ for the expermental solid mass fluxes can be calculated from Figs. 3 and 4 and relation

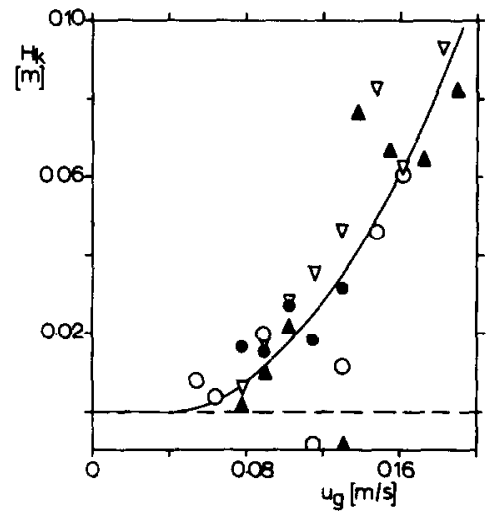

Fig 7 Height of a true mass transfer unit versus superficial gas velocity Symbols see Fig 3 .

(1b). The height of an overall dispersion unit as defined in eqn. (9) can be determined from Fig. 6. The different parameters affecting column performance are plotted in Fig. 8. From this Figure it is clear that at low gas velocities axial mixing of the solid phase is the limiting factor for column performance but it is also clear that mass transfer limitations become important at high gas velocities. For the present conditions the height of a true mass transfer unit in the region of interest corresponds to 4 - 8 Pall nng layers.

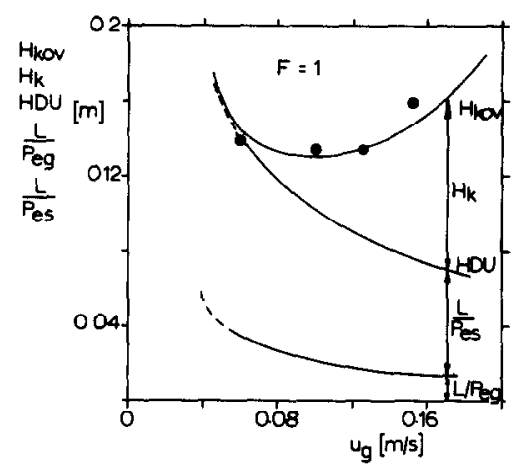

Fig 8 Different factors determining column performance as a function of the superficial gas velocity for $F=1$ 


\section{CONCLUSIONS}

The height of an overall mass transfer unit has been measured in a gas-solid packed column at tnckle flow by the steady state adsorption of freon-12. From the independently determined extraction factor and axial dispersion of both phases the height $H_{k}$ of a true transfer unit has been calculated using different approximating solutions for the mass transfer model with axially dispersed plug flow in both phases.

The results obtained with the approximations of Stemerding and Zuiderweg, Miyauchi and Vermeulen, Mecklenburgh and Hartland, and Rod are very close, differences being found to lie within the experimental error.

$H_{k}$ is approximately independent of the solid mass flux and increases with increasing gas velocity. At low gas velocities axial dispersion of the gas and especially of the solid phase is the determining factor for column performance. At higher gas velocities mass transfer limitations become important. For conditions of practical interest, the height of a true transfer unit corresponds to 4 - 8 Pall nng layers for our system.

\section{ACKNOWLEDGMENT}

The authors are very grateful to DSM for financial support during the present investigation.

\section{APPENDIX A}

Expressions for the number of transfer units Various authors have given approximate solutions for the set of eqns. (3) - (6). Here we want to express their results in terms of the number of overall transfer units.

\section{Beek [12]}

Using the zeroth moment of the concentration distributions along the column axis Beek derved an expression for the height equivalent to a theoretical stage in an infinitely long column:

$$
\begin{aligned}
& \frac{H_{\mathrm{ETS}}}{L}=\frac{F \ln F}{2(F-1)}\left\{\frac{1}{N_{k}}+\frac{1}{F \mathrm{Pe}_{\mathrm{g}}}+\frac{1}{\mathrm{Pe}_{\mathrm{s}}}+\left[\left(\frac{1}{N_{k}}+\right.\right.\right. \\
& \left.\left.\left.+\frac{1}{F \mathrm{Pe}_{\mathrm{z}}}+\frac{1}{\mathrm{Pe}_{\mathrm{s}}}\right)^{2}+\frac{4}{N_{k} F}(F-1)\left(\frac{1}{\mathrm{Pe}_{\mathrm{g}}}-\frac{1}{\mathrm{Pe}_{\mathrm{s}}}\right)\right]^{1 / 2}\right\}
\end{aligned}
$$

The ratio of the height equivalent to a theoretical stage and the column length is related to the number of overall transfer units (e g ref. 5):

$\frac{1}{N_{k \text { ov }}}=\frac{H_{\mathrm{ETS}}}{L} \frac{F-1}{\ln F}$

The boundary conditions for this approximation are such that we cannot use eqns. (A1) and (A2) for our expenmental set-up.

\section{Stemerding and Zulderweg [5]}

Starting from the expression for the height of an overall transfer unit for the limiting case $F=1$ as given by Miyauch 1 and Vermeulen [4], Stemerding and Zuiderweg derned empurical correction factors for the general case where $F \neq 1$. Rewritten in our terms the followng expressions were obtained:

$\frac{1}{N_{k \text { ov }}}=\frac{1}{N_{k}}+\frac{h^{*} / L}{1+0.8 h^{*} \ln F / L(F-1)}$

where

$\frac{h^{*}}{L}=\frac{F}{f_{\mathrm{g}} \mathrm{Pe}_{\mathrm{g}}}+\frac{1}{f_{\mathrm{s}} \mathrm{Pe}_{\mathrm{s}}}$

$f_{\mathrm{s}}$ and $f_{\mathrm{s}}$ are given by

$f_{\mathrm{z}}=\frac{0.1 N_{k}+1}{0.1 N_{k}+1 / F}$

and

$f_{\mathrm{s}}=\frac{0.1 N_{k}+1}{0.1 N_{k}+F}$

\section{Miyauchi and Vermeulen [4]}

Starting from the exact solution in the limiting case of infinite mass transfer, Miyauchi and Vermeulen obtained correction factors for the general case. The expressions are given by

$\frac{1}{N_{k \text { ov }}}=\frac{1}{N_{k}}+\frac{h^{*} / L}{1+h^{*} \ln F / L(F-1)}$

where

$\frac{h^{*}}{L}=\frac{F}{f_{\mathrm{g}} \mathrm{Pe}_{\mathrm{g}}}+\frac{1}{f_{\mathrm{s}} \mathrm{Pe}_{\mathrm{s}}}$

$f_{\mathrm{g}}$ and $f_{\mathrm{s}}$ may be obtained from

$f_{\mathrm{g}}=\frac{N_{k}+6.8 F^{-0.5}}{N_{k}+6.8 F^{-15}}$

and 
36

$$
f_{\mathrm{s}}=\frac{N_{k}+6.8 F^{-05}}{N_{k}+6.8 F^{05}}
$$

Mecklenburgh and Hartland $[13,16]$

These authors divided the column into three parts, two end regions and a central region which was assumed to be openended. Their approximation may be rearranged to

$N_{k \text { ov }}=\frac{1}{F-1}\left[\mu_{1}-\left(\frac{\mu_{1}}{\mu_{2}}-\frac{\mu_{1}}{\mu_{3}}\right)-\ln \left(\frac{\mu_{1}^{-1}--\mathrm{Pe}_{\mathrm{g}}^{-1}}{\mu_{1}^{-1}+\mathrm{Pe}_{\mathrm{s}}^{-1}}\right)\right]$

where

$\mu_{1}=\frac{(F-1) \mathrm{Pe}_{\mathrm{g}} \mathrm{Pe}_{\mathrm{s}} N_{k}}{\mathrm{Pe}_{\mathrm{g}} \mathrm{Pe}_{\mathrm{s}}+\left(\mathrm{Pe}_{\mathrm{g}}+F \mathrm{Pe}_{\mathrm{s}}\right) N_{k}}$

and $\mu_{2}$ and $\mu_{3}$ are the positive and negative roots of

$$
\begin{aligned}
\mu^{2} & +\mu\left(\mathrm{Pe}_{\mathrm{s}}-\mathrm{Pe}_{\mathrm{g}}\right)-\left[N_{k}\left(\mathrm{Pe}_{\mathrm{g}}+F \mathrm{Pe}_{\mathrm{s}}\right)+\right. \\
& \left.+\mathrm{Pe}_{\mathrm{g}} \mathrm{Pe}_{\mathrm{s}}\right]=0
\end{aligned}
$$

This approximation is exact when there is no backmixing, or for equilibrium, but it may only be appled if the "linearity rule" derived by Mecklenburgh and Hartland [16] is fulfilled.

\section{$\operatorname{Rod}[14]$}

Taking the closed-closed boundanes into account Rod derived an expression for the height of an overall transfer unit. In terms of the number of transfer units his expressions are given by

$\frac{1}{N_{k \text { ov }}}=\frac{1}{N_{k}}+\frac{1}{f_{\mathrm{g}} \mathrm{Pe}_{\mathrm{g}}}+\frac{F}{f_{\mathrm{g}} \mathrm{Pe}_{\mathrm{s}}}$

where $f_{\mathrm{s}}$ and $f_{\mathrm{s}}$ are given by

$f_{\mathrm{g}}=\frac{1}{\Phi_{\mathrm{s}}}+(1-F) \frac{N_{\mathrm{k} \text { ov }}}{\mathrm{Pe}_{\mathrm{g}}}$

and

$f_{\mathrm{s}}=\frac{1}{\Phi_{\mathrm{s}}}-(1-F) \frac{N_{k \text { ov }}}{\mathrm{Pe}_{\mathrm{s}}}$

The correction factors $\Phi_{g}$ and $\Phi_{s}$ stem from the ratio of the dimensionless variance of the residence time distribution for a closedclosed and an open-open system for dispersion:

$\Phi_{\mathrm{g}}=1-\frac{1}{\mathrm{Pe}_{\mathrm{g}}}\left[1-\exp \left(-\mathrm{Pe}_{\mathrm{z}}\right)\right]$

and
$\Phi_{\mathrm{s}}=1-\frac{1}{\mathrm{Pe}_{\mathrm{s}}}\left[1-\exp \left(-\mathrm{Pe}_{\mathrm{s}}\right)\right]$

\section{Limiting case $\mathrm{F}=1$}

For the limiting case where the extraction factor is equal to unity, which is of practical interest, the various approximations are simplified to

$\frac{1}{N_{k \text { ov }}}=\frac{1}{N_{k}}+\frac{1}{\mathrm{Pe}_{\mathrm{g}}}+\frac{1}{\mathrm{Pe}_{\mathrm{s}}}$

Usually eqn. (A19) is expressed in terms of the heights of the transfer units

$$
\begin{array}{rlrl}
H_{k \text { ov }} & =H_{k}+\frac{L}{\mathrm{Pe}_{\mathrm{g}}}+\frac{L}{\mathrm{Pe}_{\mathrm{s}}} & & F=1 \\
& =H_{k}+H_{\mathrm{DU}} & L \gg H_{\mathrm{DU}}
\end{array}
$$

Equation (A20) expresses the height of an overall transfer unit as a sum of the height of a true transfer unit and the height of an overall dispersion unit.

\section{NOMENCLATURE}

a surface area per cubic metre of column, $\mathrm{m}^{2} / \mathrm{m}^{3}$

$a_{\mathrm{int}} \quad$ internal surface area of solid per cubic metre of solid, $\mathrm{m}^{2} / \mathrm{m}^{3}$

$a_{p} \quad$ surface area of packing per cubic metre of column, $\mathrm{m}^{2} / \mathrm{m}^{3}$

$\mathrm{Bo}_{\mathrm{g}} \quad\left(=u_{\mathrm{g}} d_{\mathrm{p}} / \epsilon D_{\mathrm{g}}\right)$, Bodenstein number for gas phase

$\mathrm{Bo}_{\mathrm{s}} \quad\left(=u_{\mathrm{s}} d_{\mathrm{p}} / \beta D_{\mathrm{s}}\right)$, Bodenstein number for solid phase

$C_{\mathrm{g}}$ freon concentration in gas phase, $\mathrm{kg} / \mathrm{m}^{3}$

$C_{s}$ freon concentration on solid phase, $\mathrm{kg} / \mathrm{m}^{2}$

$d_{\mathrm{p}} \quad$ nominal packing diameter, $\mathrm{m}$

$D$ dispersion coefficient, $\mathrm{m}^{2} / \mathrm{s}$

$f_{\mathrm{g}} \quad$ correction factor for gas phase (eqns. (A5) and (A9))

$f_{\mathrm{s}} \quad$ correction factor for solid phase (eqns. (A6) and (A10))

$F \quad\left(=u_{\mathrm{g}} / m a_{\mathrm{unt}} u_{\mathrm{s}}\right)$, extraction factor

$h^{*} \quad$ constant defined in eqns. (A4) and (A8), $\mathrm{m}$

$H_{\text {ETS }}$ height equivalent to a theoretical stage, $\mathrm{m}$

$H_{\text {DU }}$ height of overall dispersion unit defined in eqn. (9), $\mathrm{m}$

$H_{k} \quad\left(=u_{g} / k a\right)$, height of true transfer unit, $m$ 
$H_{k \text { ov }}\left(=L / N_{k \text { ov }}\right)$, helght of overall transfer unit, $\mathrm{m}$

$L \quad$ column length, $m$

$m$ freon-12 adsorption equilibrium constant, $m$

$N \quad$ number of rings per cubic metre of column, $\mathrm{m}^{-3}$

$N_{k} \quad\left(=k a L / u_{\mathrm{g}}\right)$, number of true transfer units

$N_{k \text { ov }}$ number of overall transfer units defined in eqns. (1a), (1b)

$\mathrm{Pe}_{\mathrm{g}} \quad\left(=\mathrm{Bo}_{\mathrm{g}} L / d_{\mathrm{p}}=u_{\mathrm{g}} L / \epsilon D_{\mathrm{g}}\right)$, Peclet number for gas phase

$\mathrm{Pe}_{\mathrm{s}} \quad\left(=\mathrm{Bo}_{\mathrm{s}} L / d_{\mathrm{p}}=u_{\mathrm{s}} L / \beta D_{\mathrm{s}}\right)$, Peclet number for solid phase

$S$ solid mass flux, $\mathrm{kg} / \mathrm{m}^{2} \mathrm{~s}$

$u \quad$ superficial velocity, $\mathrm{m} / \mathrm{s}$

$x \quad$ length coordinate, $\mathrm{m}$

\section{Greek symbols}

$\beta \quad$ solid hold-up (volume of solid/volume of column)

$\delta \quad$ wall thickness of $\mathrm{nng}, \mathrm{m}$

$\epsilon \quad$ volume fraction of gas phase (volume of gas/volume of column)

$\epsilon_{p} \quad$ void fraction of packung

$\mu \quad$ constant defined in eqn. (A13)

$\mu_{1}$ constant defined in eqn. (A12)

$\mu_{2}$ positive root of eqn. (A13)

$\mu_{3} \quad$ negative root of eqn. (A13)

$\xi \quad$ dimensionless length coordinate

$\Phi$ correction factor (eqns. (A14) and (A15))

\section{Subscripts}

g gas phase

in external, located at inlet of either phase out external, located at outlet of either phase

s solıd phase

\section{REFERENCES}

1 G Claus, $F$ Vergnes and P Le Goff, Can $J$ Chem Eng , 54 (1976) 143

2 A W M Roes and W P M van Swaay, Chem Eng $J, 17(1979) 81$

3 A W M Roes and W P M van Swaan, Chem Eng $J, 18(1979) 13$

$4 \mathrm{~T}$ Miyauch and T Vermeulen, Ind Eng Chem Fundam , 2 (1963) 113

$5 \mathrm{~S}$ Stemerding and F J Zurderweg, Chem Eng, 168 (May) (1963) CE 156

6 P V Danckwerts, Chem Eng Scl, 2 (1953) 1

7 C A Sleicher, AIChE J, 5 (1959) 145

$8 \mathrm{~S}$ Hartland and J C Mecklenburgh, Chem Eng Sct , 21 (1966) 1209

9 M I Brittan, Chem Eng Scl, 22 (1967) 1019

10 V K Mathur and $R$ M Wellek, Can $J$ Chem Eng , 54 (1976) 90

11 T Misek and V Rod, in C Hanson (ed ), Recent Advances in Ltquid-Liquid Extractıon, Pergamon Press, Oxford, 1976

12 W J Beek, Chem Weekbl, 58 (1962) 37

$13 \mathrm{~J} \mathrm{C}$ Mecklenburgh and S Hartland, Int Chem Symp Ser No 26 (1967) 115

14 V Rod, Coll Czech Chem Commun, 34 (1969) 387

$15 \mathrm{~W}$ Bohle and W P M van Swaau, Proc 2nd Int Conf Fluid, Cambridge Univ Press, 1978

16 J. C Mecklenburgh and S Hartland, The Theory of Backmixing, Wiley-Interscience, London, 1975 